\title{
Achados ultrassonográficos em toxocaríase ocular
}

\section{Ultrasonographic findings in ocular toxocariasis}

\author{
Fábio Barreto Morais ${ }^{1,2}$, Ana lúcia Maciel ${ }^{1}$, Tiago Eugênio Farias e Arantes² ${ }^{2}$ Cristina Muccioli² ${ }^{2}$ Norma Allemann ${ }^{1}$
}

\section{RESUMO}

Objetivo: Avaliar achados ultrassonográficos nas três principais formas de apresentação da toxocaríase ocular (granulomas de periferia e polo posterior e endof talmite crônica), em pacientes com diagnóstico confirmado de toxocaríase ocular. Métodos: Foram analisados no estudo 11 pacientes (11 olhos), de forma prospectiva, com diagnóstico de toxocaríase forma ativa, com teste ELISA positivo. Os pacientes foram submetidos ao exame de ultrassonografia ocular (transdutor $10 \mathrm{MHz}$, técnica de contato).

Resultados: Na série de 11 pacientes, com idade média de 7,9 anos (variando de 2 a 17 anos), $73 \%$ homens, referiram contato prévio com cães (91\%), e com solo (50\%), sem referência à perversão do apetite. Na avaliação dos olhos comprometidos (11 olhos) o exame oftalmológico revelou a seguinte distribuição das três formas de toxocaríase ocular: 7 (63,6\%), granuloma de polo posterior; 1 (9,1\%), endoftalmite crônica; 2(18,2\%), granuloma periférico; e 1 (9,1\%), quadro associado de granuloma de polo posterior e endoftalmite crônica. Acuidade visual comprometida: sem percepção luminosa (3 olhos, 27,3\%); visão de vultos (4 olhos, 36,4\%); contar dedos a $10 \mathrm{~cm}$ (1 olho, 9,1\%); 20/200 (1 olho, 9,1\%); 20/70 (1 olho, 9,1\%); indeterminado (1 olho, 9,1\%). Sorologia para Toxocara canis foi positiva (teste ELISA) em 100\% dos casos. Oftalmoscopia fo difícil ou impossível em 64\% dos casos devido à opacidade de meios. Características ultrassonográficas observadas: membranas vítreas com retina aplicada (100\%); lesões de parede (granulomas) com refletividade alta (80\%) ou média (20\%).

Conclusão: $\bigcirc$ achado ultrassonográfico mais consistente no olho portador de toxocaríase foi a presença de massa retiniana de alta refletividade, localizada no polo posterior ou periferia, que pode ser calcificada, e que apresenta como principal característica a aderência de membranas vítreas. Em combinação com a história exame clínico e sorologia, a ultrassonografia pode ajudar no diagnóstico da toxocaríase ocular, principalmente nos casos com opacidade de meios.

Descritores: Toxocaríase/diagnóstico;Toxocaríase/parasitologia;Toxocaríase/ultras sonografia;Ultrassonografia ocular; Granuloma;Uveíte; ELISA; Infecções oculares parasitárias;Toxocara; Doenças retinianas/parasitologia;Doenças retinianas/ultrassonografia

\begin{abstract}
Purpose: To evaluate ophthalmic ultrasound findings in the three presentation forms of ocular toxocariasis (peripheralorposteriorpolegranulomas and chronicendophthalmitis), in patients with confirmed diagnosis of ocular toxocariasis.

Methods: 11 patients (11 eyes) with clinical and confirmed diagnosis of active ocular toxocariasis, presented positive ELISA test, were analyzed, prospectively, in the study. The patients were submitted to an ocular ultrasound examination $110-\mathrm{MHz}$ transducer, contact technique).

Results: In the series of 11 patients, mean age was 7.9 years-old (range from 2 to $17 \mathrm{y}$ ), $73 \%$ male, referring previous contact with dogs (91\%), and with the soil (50\%), no referral of appetite perversion. In the analyses of compromised eyes (11 eyes), the ophthalmoscopic examination revealed the following distribution of the 3 forms of ocular toxocariasis: 7 cases (63.6\%), posterior pole granuloma; 1 (9.1\%), chronic endophthalmitis; 2 (18.2\%), peripheral granuloma; and 1 (9.1\%), posterior pole granuloma associated with chronic endophthalmitis. Visual acuityimpairment:nolightperception (3eyes, 27.3\%); handmotion (4 eyes, 36.4\%); counting fingers at $10 \mathrm{~cm}$ (1 eye, 9.1\%); 20/200 (1 eye, 9.1\%); $20 / 70$ (1 eye, 9.1\%); undefined (1 eye, 9.1\%). Serology was positive to Toxocara canis (ELISA test) in 100\% of the cases. Ophthalmoscopy was difficult or impossible in $64 \%$ of the cases due to the media opacity. Ultrasound findings noted were vitreous membranes with retinal attachment (100\%); parietal lesions (granulomas) with high (80\%) or medium (20\%) reflectivity. Conclusion: The most consistent ultrasound finding in the eye with toxocariasis was a high-reflectivity retinal mass, located in posteriorpoleorperiphery, which may becalcified, and which has as main characteristic the adherence of vitreous membranes. In addition to clinical history, systemic evaluation and serology, the ultrasound can help in the diagnosis of ocular toxocariasis, especially in media opacities.
\end{abstract}

Keywords: Toxocariasis/diagnosis; Toxocariasis/parasitology; Toxocariasis/ultrasonography; Granuloma; Uveitis; Enzyme-linked immunosorbent assay; Eye infections, parasitic; Toxocara; Retinal diseases/parasitology; Retinal diseases/radiography; Retinal diseases/ ultrasonography

\section{INTRODUÇÃO}

A infestação por larva migrans visceral foi primeiramente descrita por Beavis et al., definindo uma síndrome clínica caracterizada por hepatomegalia, febre, eosinofilia crônica e hipergamaglobulinemia ${ }^{(1)}$. A doença é causada pelos nematódeos Toxocara canis e Toxocara cati, parasitas específicos que infectam os intestinos dos cachorros e gatos, respectivamente. Quando os ovos dos parasitas chegam ao intestino humano, as larvas são liberadas e migram via corrente sanguínea e linfática, acometendo o fígado, pulmões, olhos e outros órgãos ${ }^{(2)}$.

Toxocaríase ocular é uma doença rara, sendo o espectro da doença clínica difícil de estabelecer ${ }^{(3)}$. Wilkinson e Welch classificaram a toxocaríase ocular em: endoftalmite difusa, granulomas de polo posterior e periferia ${ }^{(4)}$. Stewart et al., relataram que a toxocaríase re- presentou 1\% em sua série de casos de uveíte, com as seguintes apresentações: granuloma periférico (50\%), granuloma de polo posterior (25\%) e inflamação vítrea mimetizando endoftalmite (25\%) ${ }^{(5)}$.

O diagnóstico de certeza é feito pela demonstração da larva ou fragmento da sua cápsula no sítio da lesão, sendo este procedimento raramente feito ${ }^{(6)}$. Desta forma o diagnóstico da doença se baseia em dados clínico-epidemiológicos, testes imunológicos, exames laboratoriais e de imagem ${ }^{(7-9)}$.

Dentre os exames complementares para o diagnóstico da toxocaríase ocular, podem ser úteis testes imunológicos como ELISA (técnica imunoenzimática usada para determinar o nível de anticorpos do Toxocara canis presente no soro), hemograma, radiografia, tomografia computadorizada, eletrofisiologia ocular e ultrassonografia 
ocular, sendo este último importante principalmente no diagnóstico diferencial com retinoblastoma, no qual se encontra depósitos de cálcio (7,8,10-12). A presença de calcificação não exclui o diagnóstico de toxocaríase ${ }^{(10)}$.

Não há achado patognomônico da toxocaríase ocular ao exame ultrassonográfico. Os granulomas causados pela toxocaríase foram descritos como massas retinianas com refletividade interna alta, podendo se associar com descolamento tracional de retina e traves vítreas ${ }^{(8,10-12)}$. À ultrassonografia, a toxocaríase ocular é caracterizada por uma tríade de achados: massa sólida periférica de alta refletividade (granuloma); trave vítrea ou membranas vítreas que se estendem a partir do polo posterior e do granuloma; descolamento tracional de retina ou prega de retina que se estende do granuloma ao polo posterior. Esses achados são encontrados tanto em pacientes que apresentam a forma de endoftalmite crônica quanto nos pacientes com granuloma periférico visível. O granuloma posterior solitário causado pela toxocaríase foi descrito como lesão sub-retiniana, isolada, sem envolvimento vítreo ou tração retiniana ${ }^{(10)}$.

A ultrassonografia tem sido realizada em casos de toxocaríase ocular para determinação do tipo de acometimento e para diagnóstico diferencial com lesões tumorais de outras etiologias, útil na avaliação em casos com opacidade de meios.

O objetivo deste estudo é avaliar achados ultrassonográficos nas três principais formas de apresentação da toxocaríase ocular (granuloma periférico, granuloma de polo posterior e endoftalmite crônica) em pacientes com diagnóstico confirmado de toxocaríase ocular.

\section{MÉTODOS}

Foram analisados no estudo 11 pacientes (11 olhos), de forma prospectiva, atendidos no Departamento de Oftalmologia da Universidade Federal de São Paulo no segundo semestre de 2007, com diagnóstico clínico e sorológico confirmado de toxocaríase ocular.

O exame oftalmológico foi composto de medida da acuidade visual com melhor correção óptica; biomicroscopia de segmento anterior e anexos, tonometria e fundoscopia sob midríase por oftalmoscopia binocular indireta com lente de 20 dioptrias.

Os pacientes foram submetidos ao exame ultrassonográfico, com transdutor de $10 \mathrm{MHz}$ (Ultrascan, Alcon), técnica de contato, utilizando modos A e B, único examinador.

Os dados coletados incluíram características ultrassonográficas das lesões intraoculares, tais como: refletividade interna, tamanho,

\begin{tabular}{|c|c|c|c|c|c|}
\hline Caso & $\begin{array}{l}\text { Contato } \\
\text { com cães }\end{array}$ & $\begin{array}{l}\text { Tanques } \\
\text { de areia }\end{array}$ & Estrabismo & $\begin{array}{c}\text { Fundoscopia } \\
\text { possível }\end{array}$ & $\begin{array}{l}\text { História } \\
\text { de LMV }\end{array}$ \\
\hline 1 & $\operatorname{Sim}^{*}$ & Não & Não & Sim & Não \\
\hline 2 & Sim & Não & Sim & Não & Não \\
\hline 3 & Sim & Sim & Não & Difícil & Não \\
\hline 4 & $\operatorname{Sim}^{*}$ & Não & $\operatorname{Sim}^{* *}$ & Sim & Não \\
\hline 5 & $\mathrm{Sim}^{*}$ & Não & Sim & Não & Não \\
\hline 6 & $\operatorname{Sim}^{*}$ & Sim & Sim & Sim & Não \\
\hline 7 & $\operatorname{Sim}^{*}$ & $\mathrm{Sim}$ & Não & Não & Não \\
\hline 8 & $\operatorname{Sim}^{*}$ & $\operatorname{Sim}$ & Não & Sim & Não \\
\hline 9 & $\operatorname{Sim}^{*}$ & Sim & Sim & Difícil & Não \\
\hline 10 & Não & Não & Não & Difícil & Não \\
\hline 11 & Sim & Não & Não & Não & Não \\
\hline
\end{tabular}

$\mathrm{LMV}=$ larva migrans visceral

* = contato com filhotes de cães

** = estrabismo como primeiro sinal limites, localização, achados associados (descolamento de retina, pregas retinianas, traves vítreas, calcificações), aspecto do vítreo.

\section{RESULTADOS}

Esta série incluiu 11 pacientes, sendo a maioria do sexo masculino, 8 (72,7\%) pacientes, e 3 (27,3\%) do feminino. Com relação à idade de diagnóstico, variou de 2 a 17 anos. Todos os 11 (100\%) pacientes apresentaram sorologia positiva para Toxocara canis.

Com relação aos achados clínicos e epidemiológicos, o estrabismo esteve presente em 5 (45,5\%) casos, sendo em 1 (9\%) destes, o primeiro sinal. Dez (91\%) pacientes tiveram contato prévio com cães, sendo que 7 (63,6\%) eram filhotes (idade inferior a 6 meses), apenas 1 (9\%) paciente não relatava contato com cães. Cinco (45,5\%) pacientes tiveram contato constante com tanques de areia. Nenhum paciente da presente série apresentou história associada de larva migrans visceral. (Tabela 1)

Foram avaliados no total 11 olhos de portadores de toxocaríase ocular, dos quais $7(63,6 \%)$ apresentavam granuloma de polo posterior, 1 (9,1\%) endoftalmite crônica, 2 (18,2\%) granuloma periférico e $1(9,1 \%)$ apresentava quadro associado de granuloma de polo posterior e endoftalmite crônica. Acuidade visual no momento do exame: sem percepção luminosa (3 olhos, 27,3\%); visão de vultos (4 olhos, 36,4\%); conta dedos a $10 \mathrm{~cm}$ (1 olho, 9,1\%); 20/200 (1 olho, 9,1\%); 20/70 (1 olho, 9,1\%); indeterminado (1 olho, 9,1\%). O olho direito foi envolvido em 5 (45,5\%) pacientes e o olho esquerdo em 6 (54,5\%), não houve caso de bilateralidade. (Tabela 2)

Na série de 11 olhos com toxocaríase ocular, 10 olhos apresentavam a forma de granuloma. Quanto às características ultrassonográficas dos granulomas, observou-se: refletividade interna alta em 8 olhos (80\%), e média a alta em 2 (20\%); a superfície da lesão foi irregular em 8 casos (80\%), regular em 2 (20\%); o conteúdo do granuloma foi predominantemente homogêneo em 8 dos casos (80\%); os limites imprecisos em 7 (70\%); a localização foi peripapilar em 5 (50\%), temporal em 3 (30\%), e nasal em 2 (20\%). Em 100\% dos casos foram evidenciadas membranas vítreas aderidas ao granuloma. (Tabela 3; Figura 1)

O achado de calcificação à ultrassonografia esteve presente em 2 (20\%) dos granulomas, em outros 2 olhos, o cálcio fazia parte do processo de atrofia bulbar. (Tabela 2; Figura 2)

A importância da ultrassonografia se fez evidente com relação à dificuldade em avaliação da fundoscopia. Em 7 (64\%) pacientes, esta avaliação era difícil ou impraticável. (Figura 3)

\section{DISCUSSÃO}

A infecção intraocular devido ao Toxocara canis pode produzir várias manifestações ${ }^{(10)}$. Foram descritas nove formas de apresentação: endoftalmite, granuloma de polo posterior, granuloma periférico, larva móvel sub-retiniana, neurorretinite subaguda unilateral difusa (DUSN), neurite óptica, ceratite, conjuntivite e acometimento do cristalino ${ }^{(7,13)}$. Além dessas, outras manifestações menos frequentes foram descritas tais como hemorragia retiniana isolada, embolização larvária, iridociclite, larva móvel intravítrea e hipópio(12). As três principais formas de apresentação da toxocaríase ocular são os granulomas de polo posterior, granuloma periférico e a endoftalmite crônica ${ }^{(10)}$.

Na série apresentada, a idade do início dos achados oculares da toxocaríase variou entre 2 e 17 anos, com média de 7,9 anos, observando-se dados semelhantes ao da literatura ${ }^{(7)}$. Alguns autores referiram 30 casos, com idade entre 2 e 26 anos, média de 14 anos, e Lacerda relata, em sua série de casos, pacientes de 3 a 24 anos (média de 8,6 anos) $)^{(6,12)}$.

No presente estudo não se observou bilateralidade, o que condiz com a literatura, apesar de existirem relatos isolados de casos bilaterais ${ }^{(6)}$

Wan et al. ${ }^{(10)}$, assim como Lacerda ${ }^{(12)}$ relataram localização preferencial do granuloma de toxocaríase na periferia. Na série de pa- 
Tabela 2. Apresentação clínica da toxocaríase ocular

\begin{tabular}{cccccccc}
\hline Caso & $\begin{array}{c}\text { Idade } \\
\text { (anos) }\end{array}$ & Sexo & Olho & Acuidade visual & $\begin{array}{c}\text { Sorologia } \\
\text { (ELISA) }\end{array}$ & $\begin{array}{c}\text { Apresentação } \\
\text { calcificaçãó }\end{array}$ \\
\hline 1 & 8 & M & OD & Vultos & + & Granuloma de polo posterior & + \\
2 & 8 & M & OD & Vultos & + & Granuloma periférico & + \\
3 & 7 & M & OD & SPL & + & Granuloma de polo posterior & e endoftalmite crônica \\
& & & Granuloma de polo posterior & - \\
4 & 5 & M & OE & CD 10 cm & + & Granuloma periférico & $+^{*}$ \\
5 & 11 & M & OD & SPL & + & Granuloma de polo posterior & - \\
6 & 6 & M & OE & 20/200 & + & Granuloma de polo posterior & - \\
7 & 17 & M & OE & Vultos & + & Granuloma de polo posterior & - \\
8 & 8 & F & OE & $20 / 70$ & + & Granuloma de polo posterior & - \\
9 & 2 & F & OE & - & Granuloma de polo posterior & - \\
10 & 7 & F & OD & Vultos & + & Endoftalmite crônica & $+^{*}$ \\
11 & 8 & M & OE & SPL & + & + & \\
\hline
\end{tabular}

$M=$ masculino; $F=$ feminino; $O D=$ olho direito; $O E=$ olho esquerdo; $C D=$ conta dedos; $S P L=$ ausência de percepção luminosa

* = calcificação difusa da parede

Tabela 3. Características ultrassonográficas da apresentação de toxocaríase ocular na forma de granuloma (n=10 olhos)

\begin{tabular}{|c|c|c|c|c|c|c|}
\hline Caso & $\begin{array}{l}\text { Refletividade } \\
\text { interna }\end{array}$ & Superfície & Conteúdo & Limites & Localização & $\begin{array}{c}\text { Membranas } \\
\text { aderidas }\end{array}$ \\
\hline 1 & Média a alta & Regular & Heterogêno & Nítidos & Peripapilar e temporal & Sim \\
\hline 2 & Alta & Irregular & Homogêneo & Imprecisos & Temporal periferia & Sim \\
\hline 3 & Alta & Irregular & Homogêneo & Nítidos & Temporal inferior & Sim \\
\hline 4 & Alta & Irregular & Homogêneo & Imprecisos & Peripapilar inferior & $\operatorname{Sim}$ \\
\hline 5 & Alta & Irregular & Homogêneo & Imprecisos & Nasal inferior & $\operatorname{Sim}$ \\
\hline 6 & Alta & Regular & Homogêneo & Nítidos & Peripapilar inferior & Sim \\
\hline 7 & Média a alta & Irregular & Heterogêneo & Imprecisos & Nasal superior & Sim \\
\hline 8 & Alta & Irregular & Homogêneo & Imprecisos & Peripapilar & Sim \\
\hline 9 & Alta & Irregular & Homogêneo & Imprecisos & Peripapilar inferior & Sim \\
\hline 10 & Alta & Irregular & Homogênea & Imprecisos & Temporal inferior & Sim \\
\hline
\end{tabular}
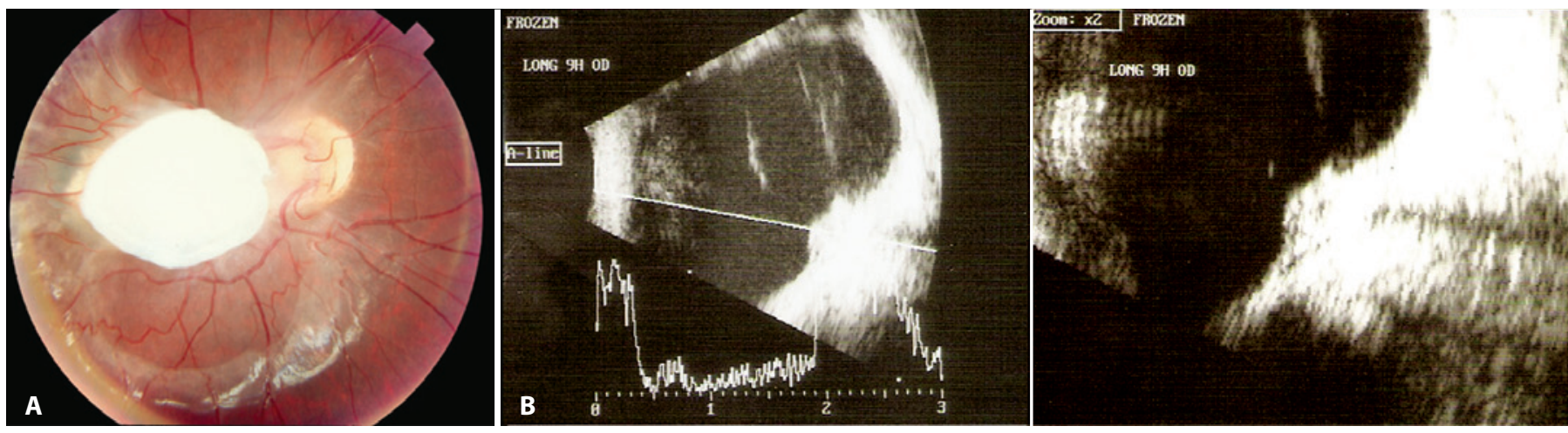

Figura 1. Sexo masculino, 12 anos, toxocaríase ocular. A) Retinografia demonstra lesão esbranquiçada, na região peripapilar, sugerindo granuloma de polo posterior; B) Ultrassonografia da lesão demonstra massa retiniana de alta refletividade, sobrelevada com aderências vítreas.

cientes, observa-se a forma polar (granuloma de polo posterior) mais frequente (73\%), apresentação referida como mais frequente em outra referência nacional(6).
A associação entre larva migrans visceral (LMV) e a forma ocular (toxocaríase ocular) é um evento raro(10), não tendo ocorrido em nenhum caso desta série. A diferença clínica entre as duas formas pode 


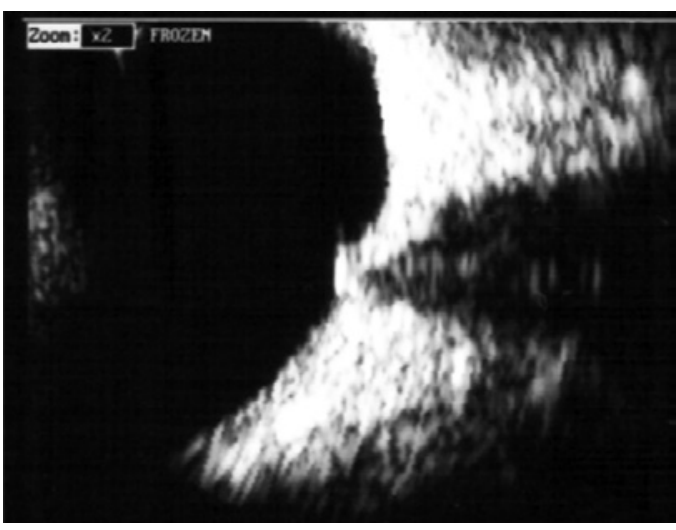

Figura 2. Sexo feminino, 17 anos, toxocaríase ocular. Ao exame ultrassonográfico, observa-se, em ganho de 65, estrutura hiperrefletiva (cálcio) no granuloma. cães com mais de 1 ano de idade, a prevalência foi menor que 20\%. Oréfice et al. ${ }^{(6)}$, em sua série de 30 casos, relataram 100\% de contato com cães em portadores de toxocaríase ocular.

O contato com o solo (parques, praças e o uso de caixas de areia nas escolas) é para alguns autores o principal fator de risco para a infecção(4). No presente estudo, determinou-se contato direto com tanques de areia em 5 dos pacientes (45,5\%).

Apesar de os 11 casos da série apresentarem sorologia positiva para toxocaríase (teste ELISA), cinco dos pacientes $(45,5 \%)$ foram acompanhados simultaneamente pelo setor de tumores oculares da Universidade de São Paulo até ser descartada definitivamente a possibilidade de retinoblastoma como causa da leucocoria, o que traduz a dificuldade diagnóstica em alguns casos.

Testes laboratoriais possuem uso limitado na toxocaríase ocular. Embora pacientes com larva migrans visceral frequentemente apresentem leucocitose com eosinofilia, este achado não ocorre na forma ocular ${ }^{(10)}$. O teste de ELISA pode ser usado na determinação dos níveis de anticorpos no soro. Infelizmente, a prevalência da soropositividade em populações pediátricas varia de 20 a 30\%(15). Oréfice et al. ${ }^{(6)}$, referiram positividade para o teste de ELISA em $88,24 \%$ dos seus 30 casos de toxocaríase ocular presumida. No presente estudo, a positividade do teste de ELISA foi $100 \%$.

Em alguns casos, com o granuloma típico observado à oftalmoscopia indireta, o diagnóstico não oferece dificuldades. Entretanto, em outros casos com leucocoria, opacidades de meios e inflamação vítrea, o uso da ultrassonografia como exame complementar se faz indispensável. Observou-se que em 7 (64\%) pacientes a realização da fundoscopia era difícil ou impraticável.

A presença de membranas aderidas ao granuloma de toxocaríase (100\% dos casos nesta série) é um dado importante em relação ao diagnóstico diferencial com o retinoblastoma, outra causa de leucocoria, sendo um achado raro neste tumor, segundo alguns autores ${ }^{(10)}$. (Figura 4)

\section{CONCLUSÃO}

No presente estudo, o achado ultrassonográfico mais consistente com o diagnóstico de toxocaríase ocular foi a presença de massa retiniana ou granuloma, de alta refletividade, que pode ser localizada no polo posterior e na periferia, calcificada ou não, apresentando como principal característica a presença de membranas vítreas aderidas.

Em combinação com a história, exame clínico e sorologia, a ultrassonografia pode auxiliar no diagnóstico da toxocaríase ocular, principalmente nos casos com opacidade de meios.
Figura 4. Sexo masculino, 12 anos. A) Imagem ultrassonográfica (modo A e B) demonstra massa de alta refletividade com múltiplas membranas aderidas; B) Destaque da refletividade interna da lesão em modo A.

\section{REFERÊNCIAS}

1. Beaver PC, Snyder CH, Carrera GM, Dent JH, Lafferty JW. Chronic eosinophilia due to visceral larva migrans; report of three cases. Pediatrics. 1952;9(1):7-19.

2. Janjetovic Z, Arar ZV, Marinic M, Pandak M. [Uveites caused by Toxocara canis]. Acta Med Croatica. 2006;60(1):63-6. Croatian.

3. Gillespie SH, Dinning WJ, Voller A, Crowcroft NS. The spectrum of ocular toxocariasis Eye (Lond). 1993;7(Pt 3 ):415-8. Comment in: Eye (Lond). 1993;7(Pt 6):810.

4. Wilkinson CP, Welch RB. Intraocular toxocara. Am J Ophthalmol. 1971;71(4):921-30.

5. Stewart JM, Cubilan LD, Cunninghan ET Jr. Prevalence, clinical features, and cause of vision loss among patients with ocular toxocariasis. Retina. 2005;25(8):1005-13.

6. Oréfice F, Boratto LM, Silva HF. Presumível toxocaríase ocular - revisão de 30 casos (1978-1989) - relato de dois casos atípicos. Rev Bras Oftalmol. 1991;50(2):31-7. 
7. Pivetti-Pezzi P. Ocular toxocariasis. Int J Med Sci. 2009;6(3):129-30.

8. Rodman J, Pizzimenti J. In vivo diagnostic imaging of ocular toxocariasis. Clin Exp Optom. 2009;92(2):146-9.

9. de Visser L, Rothova A, de Boer JH, van Loon AM, Kerkhoff FT, Canninga-van Dijk MR, et al. Diagnosis of ocular toxocariasis by establishing intraocular antibody production. Am J Ophthalmol. 2008;145(2): 369-74.

10. Wan WL, Cano MR, Pince KJ, Green RL. Echographic characteristics of ocular toxocariasis. Ophthalmology. 1991;98(1):28-32.

11. do Lago A, Andrade R, Muccioli C, Belfort R Jr. Optical coherence tomography in presumed subretinal Toxocara granuloma: case report. Arq Bras Oftalmol. 2006; 69(3):403-5.

12. Lacerda RR. Toxocaríase de 36 casos: estudo sequencial. Rev Bras Oftalmol. 1995;54(3):7-20.

13. Shields JA. Ocular toxocariasis. A review. Surv Ophthalmol. 1984;28(5):361-81.

14. Schantz PM, Glickman LT. Toxocaral visceral larva migrans. N Engl J Med. 1978;298(8): 436-9.

15. Ellis GS Jr, Pakalnis VA, Worley G, Green JA, Frothingham TE, Sturner RA, et al. Toxocara cannis infestation. Clinical and epidemiological associations with seropositivity in kindergarten children. Ophthalmology. 1986;93(8):1032-7. 